\title{
TURISMO RURAL Y DESARROLLO TERRITORIAL EN ESPACIOS INDÍGENAS DE MÉXICO
}

\author{
José Pedro Juárez Sánchez y Benito Ramírez Valverde \\ Colegio de Postgraduados, Campus Puebla, México \\ María Guadalupe Galindo Vega \\ Directora de Cultura de San Pedro Cholula, Puebla, México
}

\section{RESUMEN}

México es uno de los principales productores de café a escala mundial, lo que genera una gran cantidad de divisas al país. Sin embargo, es producido en su mayoría por indígenas en pequeñas plantaciones y viven en condiciones de extrema pobreza. Esta situación se ha acentuado a raíz de las crisis recurrentes del cultivo. Este estudio se realizó en cuatro municipios con plantaciones de café, ubicados en la sierra Nororiente de Puebla, México. La investigación se centró en la posibilidad de impulsar el agroturismo en espacios marginados, con población pobre e indígena. Los resultados muestran que el 80 por ciento de los entrevistados desea participar en actividades agroturísticas. Se concluye que mediante el apoyo a este tipo de proyectos por parte de las autoridades gubernamentales, el agroturismo puede representar una actividad complementaria a la producción de café que proporcione recursos económicos y que permita contribuir al incremento y calidad de la producción y, consecuentemente, a mejorar las condiciones de vida de la familia campesina.

Palabras clave: Café, agroturismo, indígena, pobreza, marginación, Puebla

\begin{abstract}
Mexico is one of the world main coffee producers which generates an important income for the country. However, it is mainly produced by indigenous groups in small land areas and in extremely poor conditions. This situation has become
\end{abstract}


even worse due to the frequent crisis in the crop price. This study was carried out in four municipalities where coffee is grown, located in the Sierra Nororiental of Puebla, Mexico. The research focused on the possibility of impelling agrotourism in marginalized spaces with poor indigenous population. Results show that $80 \%$ of the interviewed people are willing to participate in agrotourism activities. It is concluded that the support given by the governmental authorities to this kind of projects can make of agrotourism a supplementary activity to the production of coffee. This is expected to increase the economic resources and the quality of the production thus improves life conditions of the peasants.

Key words: coffee agrotourism, poverty, marginalization, Puebla.

\section{INTRODUCCIÓN}

A principios de la década de los 80's del siglo pasado, organismos multinacionales como el Banco Mundial (BM), Banco Interamericano de Desarrollo (BID) y el Fondo Monetario Internacional (FMI) impulsaron políticas de corte neoliberal mediante programas de ajuste estructural, principalmente en los países subdesarrollados. Esta estrategia trajo como consecuencia el abandono del modelo de Industrialización Sustitutiva de Importaciones (ISI), para implantar una política proexportadora basada en productos no tradicionales (Ramos, 1993). Con el nuevo modelo económico se fortalece a las ciudades, con el fin de comercializar y promocionar una imagen global urbana competitiva frente a otras ciudades. Éstas se transforman en productos de una city marketing atrayendo servicios, actividades comerciales, inversiones, además de la promoción creciente del turismo urbano (Sassano, 2001: 101).

Además, este modelo repercutió directamente en la calidad de vida de gran parte de la población; al respecto, diversos analistas coinciden en determinar como causa generadora en las últimas décadas de la pobreza rural, al conjunto de procesos asociados con el modelo de desarrollo que han adoptado los países latinoamericanos (IICA y BID, 2002: 12). Una de sus repercusiones ha sido el incremento de la población pobre, por lo menos en el caso de México. En este sentido, Echeverría (1998: 2) menciona que la pobreza rural aumentó de 46 por ciento en 1992 a 47 por ciento en 1994, y Lustig et al. (1997: 12) indican que entre 1989 y 1994 la pobreza, tanto extrema como moderada, registró un aumento entre los trabajadores rurales, en el sector primario y en las regiones Sur y Sureste del país. En 2004, el 28 por ciento de los habitantes en zonas rurales se encontraba en niveles de pobreza extrema y el 57 por ciento en situación de pobreza moderada; aunque sólo una cuarta parte de la población mexicana vive en zonas rurales, en estas regiones reside el 60,7 por ciento de la población en pobreza extrema y el 46,1 por ciento de los moderadamente pobres (BIRF y BM, 2005: 69). 
Los habitantes de las comunidades indígenas han sido los más afectados, no sólo por el impacto de la política agrícola seguida por el Estado mexicano, sino también por el descenso del precio internacional del café, ya que el 65 por ciento de sus productores son indígenas minifundistas y producen un tercio de la producción en México. Son los pobres de los pobres. Ante este nuevo orden económico, los pobladores del medio rural marginados de los beneficios de la globalización, impulsan nuevas formas de generación de ingresos para sobrevivir en una agricultura subsumida en la crisis. Entre las estrategias que han desarrollado destaca la diversificación de las actividades agrícolas, así como el surgimiento de actividades no agrícolas y los movimientos migratorios a las grandes ciudades y al extranjero.

Se puede decir que la agricultura minifundista está en crisis y no es capaz de generar ingresos suficientes para sostener a los miembros de una familia; al respecto, Pérez (2001: 22) menciona que existe una pérdida relativa de la significación económica y social de los sectores primario y secundario, y una evidente terciarización en los espacios rurales. Es importante destacar que la terciarización del medio rural va en aumento, pero, sobre todo, como una meta del nuevo modelo de desarrollo impulsado por los organismos multinacionales. Pérez concluye que lo rural ya no es equivalente a lo agrícola y, al mismo tiempo, que la llamada tercera revolución agrícola implica que lo agrícola no sea exclusivamente la producción primaria. Todo esto conduce a la desagrarización de la actividad productiva.

En ese sentido, se fomenta el financiamiento a proyectos turísticos en espacios rurales que presentan un gran valor natural o cultural, pero hasta el momento han sido insuficientes. Mediante estos proyectos se pretende fomentar y diversificar los atractivos turísticos del país, para incrementar la afluencia turística, generar empleos y mejorar los servicios básicos (boletín de prensa 2006). Un ejemplo de lo anterior es el municipio de estudio -Cuetzalan-, declarado como Pueblo Mágico ubicado en la sierra Nororiente de Puebla. En donde las actividades turísticas en estos espacios son bien vistas y consideradas como un instrumento para mejorar las condiciones de vida de la población que las habita.

\section{TURISMO RURAL Y DESARROLLO TERRITORIAL EN MÉXICO}

En los últimos años, la forma de promover el desarrollo ha cambiado en Latinoamérica y especialmente en México; esta nueva visión obedece fundamentalmente al cambio de modelo de desarrollo de Industrialización Sustitutiva de Importaciones (ISI) por uno de corte neoliberal. La implementación de este modelo trajo consigo profundos cambios estructurales en la economía, como es el fomento del libre mercado. Para ello fue necesario debilitar a los estados nacionales; ahora el mercado se ha convertido no sólo en el principal, sino en el único 
dispositivo de regulación económica (Linck, s/f: 1-2). El neoliberalismo cree en la apertura de las economías nacionales a los mercados globales sin intervención del Estado. Ello ha traído consigo el sacrificio de sectores no competitivos como el industrial, en aras de la competencia internacional (Kay, 1998: 10). El sector agrícola no es la excepción.

Al sector agropecuario en el modelo ISI se le asignó el papel de producir alimentos baratos para la población urbana y generar divisas mediante su exportación. Ahora la agricultura no sólo es explotada, sino excluida. Esta situación agravó la crisis del sector agrícola, y ante esto, en los espacios rurales se impulsa el surgimiento del desarrollo del territorial rural, que se define como un proceso de transformación productiva e institucional de un espacio rural, con el fin de disminuir la pobreza rural (Schejtman y Berdagué, 2004: 30). El termino de desarrollo territorial rural se basa en la revaloración del espacio rural y su geografía, como unidad de gestión que permita integrar una economía multisectorial, dimensiones políticas, sociales, culturales y ambientales, que han venido construyendo una institucionalidad dinámica, aunque compleja, y que ofrece la posibilidades de una respuesta a los errores que ha mostrado el desarrollo rural en las ultimas décadas (Echeverri y Ribero, 2003: 23). En este modelo de desarrollo se dejan de operar políticas sectoriales por políticas sustentadas en el territorio, ya que la agricultura de tipo minifundista no es capaz de generar los ingresos suficientes para satisfacer las necesidades de quienes la practican, debido al escaso apoyo que reciben del Estado y a los bajos precios de sus productos agropecuarios.

En el caso mexicano, en su implementación fue necesario que se abandonara la forma de conducir la economía por parte del Estado, es decir, se dejó la planificación tradicional que se caracterizaba por ser normativa, indicativa y sectorizada, por una planificación del desarrollo que, según sus promotores, busca mejorar la calidad de vida de su población, mediante la distribución equitativa del ingreso, y que además piensa en la conservación y regeneración de los recursos naturales y promueve la participación de los pobladores en el proceso de toma de decisiones. Es decir, que se apuesta por una planificación de abajo hacia arriba, y para su implementación, el Estado descentralizó funciones y atribuciones a los gobiernos de los estados y municipios, con el objetivo de impulsar el desarrollo en los territorios, pero México está lejos de alcanzar una distribución equitativa del ingreso; si acaso se tiene una diversificación de las actividades económicas en algunas regiones rurales del país.

Por otro lado, Silva (2002: 106-107) menciona que la generación de excedentes productivos en el mundo desarrollado, la creciente apertura del comercio internacional de productos agrarios, la constatación del papel desempeñado por 
los cultivos en la conformación de los paisajes rurales, la creciente demanda de espacios libres, está conduciendo a cambiar el papel tradicionalmente asignado a la agricultura, y a que se superponga a otros más relacionados con la provisión de bienes ambientales y culturales. A pesar de ello, la producción agropecuaria y forestal siguen siendo la principal actividad económica en los espacios rurales de México y, de acuerdo al desarrollo territorial rural, es posible promover su dinamización mediante el impulso de la agroindustrialización de los productos agropecuarios, de la producción de artesanías y de la participación de la población local en el turismo rural, es decir, se tiene que promover la diversificación productiva en las unidades de producción e impulsar el Empleo Rural No Agrícola (ERNA).

Esta nueva forma de enfrentar la crisis en la agricultura hace que tomen un lugar primordial otras actividades no agrícolas, como el turismo, en el desarrollo territorial rural, que actúa no sólo como generador de ingresos, sino también en la creación de empleos, mejoramiento de la calida de vida de la población local y en la conservación de los recursos naturales. En este sentido, Font (2006: 7) menciona que el turismo juega un rol importante en la economía de muchos países de ingresos bajos, donde la llegada de turistas internacionales superaron los 175 millones en 2005. En términos de ingresos, corresponden a un valor para estos países de 85 mil millones de dólares. De hecho, el turismo es uno de los mayores sectores generadores de divisas en un gran número de países en desarrollo y la primera fuente de divisas en 46 de los 50 países menos adelantados. La OMT (2003) argumenta que se ha convertido en un sector importante para la mayoría de los países en desarrollo y, en algunos casos, ha desbancado a la agricultura comercial y a otras industrias primarias como principal fuente de rentas nacionales, empleo e ingreso por exportaciones.

En Kenya, el turismo ha desplazado a la producción de té, café y productos hortícolas y se ha convertido en el principal generador de divisas, al igual que ha ocurrido en Costa Rica. El desarrollo del turismo ha contribuido al desarrollo de Botswana, que dejó de figurar entre los países menos desarrollados. Así mismo, el turismo ha sido vital para la economía cubana a partir de que se redujera el apoyo económico de la antigua Unión de Repúblicas Socialistas Soviéticas. Los ingresos que genera el turismo han ayudado a las economías del Caribe a afrontar el descenso de los precios de sus principales productos de exportación como el plátano y el azúcar. La incorporación del turismo en China como medio de desarrollo económico le está permitiendo alcanzar un alto índice de crecimiento en algunas zonas. Es por eso que la creciente multifuncionalidad de los espacios rurales se está viendo acompañada de la asunción de nuevas funciones, en donde el turismo puede ser una de ellas. 
Es importante mencionar que en las economías rurales deprimidas la agricultura sigue siendo la actividad dominante, es por ello, que la política territorial tiene que ir dirigida a ésta, pero a su vez tiene que buscar la diversificación de las actividades no agrícolas, sin caer en su total dependencia. En este enfoque y con relación al cambio de las funciones del medio rural, Vera et al. (1997: 134) comentan que el turismo rural hace una contribución valiosa a las economías rurales que se observa en términos financieros, de empleo, en la contribución de la financiación a la conservación del medio ambiente, de estímulo y motivación a la adopción de nuevas formas de trabajo y contribuye a dar una nueva vitalidad a las economías.

Se debe tener cuidado en no caer en ideas falsas que se tienen del turismo rural, al cual le atribuyen la solución a los problemas del desarrollo rural; es por ello importante tener en cuenta las observaciones de José Luis Andrés (2000: 47), al decir que el turismo rural es complementario más que una alternativa. Juárez y Ramírez (2007) indican que el turismo es sólo una fuente de ingresos más que se tiene que promover en los territorios rurales, pero que no se tienen que descuidar las actividades productivas que realizan los agricultores. Éstas tienen que fortalecerse y, a su vez, crear nuevas oportunidades de trabajo que permitan la generación de ingresos no agrícolas. En este mismo sentido se pronuncia Ascanio (2004: 157), al decir que el turismo rural no debería desplazar las actividades agrícolas y culturales de estos espacios geográficos, sino, por el contrario, se deben estimular y fortalecer. Pero el turismo sólo traerá beneficios económicos si va dirigido a los habitantes de la comunidad, ya que muchas veces, y específicamente en el ecoturismo, los beneficiados son los operadores de empresas turísticas. Lo que se busca es fortalecer en el medio rural las actividades agrícolas e impulsar la diversificación de actividades no agrícolas, entre ellas el turismo.

La promoción del turismo rural en México se da en dos vertientes. La primera es a través de la inversión del gobierno federal en programas de desarrollo turístico de carácter general, en el cual involucra de manera marginal al turismo rural (Juárez y Ramírez, 2006) y en donde el turismo de sol y playa es prioritario en la economía y en la política turística mexicana. En esta vertiente destaca el programa de Pueblos Mágicos al que pertenece el municipio de Cuetzalan y que forma parte de este estudio. En la segunda se encuentra el turismo rural, que se basa fundamentalmente en los inmuebles de las antiguas haciendas del México porfiriano; éstas han iniciado su operación con grandes presupuestos para su remodelación y rescate: es el caso de las haciendas henequeneras en Yucatán y del programa Haciendas y Casas Rurales de Jalisco (Amaya, 2005: 54), así como las haciendas cocoteras en el estado de Tabasco. 
En el país, en el 2000, existían 15 empresas comunitarias apoyadas por el Fondo Nacional de Empresas Sociales (FONAES) de un total de 442 empresas operadoras de ecoturismo y turismo de aventura. Esta actividad se concentra principalmente en siete estados: Quintana Roo (17,2\%), Distrito Federal (14.2\%), Baja California Sur (8,9\%), Oaxaca (8,7\%), Chiapas (8,5\%), Jalisco $(8,4 \%)$ y Veracruz $(7,6 \%)$ (SECTUR, 2001). Actualmente existen un total de 1.239 empresas y proyectos orientados a atender el ecoturismo y turismo rural, de las cuales 872 están en operación y 367 están en etapa de desarrollo. De dicha oferta, 325 son empresas privadas y 914 comunitarias. Entre los estados con mayor oferta destacan Chiapas, Distrito Federal, Oaxaca, Michoacán, Puebla, Veracruz y Quintana Roo (boletín de prensa, 2006). Este tipo de empresas están ubicadas espacialmente en la denominada Mesoamérica, que se caracteriza por tener un importante patrimonio natural y cultural capaz de atraer a los turistas.

\section{EL TURISMO EN EL ESTADO DE PUEBLA}

Bajo el modelo neoliberal, el Estado reestructuró la forma de intervenir en el fomento del desarrollo económico y social del país; en el sector turístico promueve fundamentalmente el turismo de playa en los Centros Integralmente Planeados (CIP) como Cabo San Lucas y Loreto en el estado de Baja California Sur; Cancún en Quintana Roo y Bahías de Huatulco en Oaxaca. Este tipo de turismo constituye un elemento básico para la economía de México. En menor intensidad promueve el turismo cultural o de ciudad en los principales centros poblacionales del país; entre ellos destaca la capital de la república, Guadalajara, Monterrey, Guanajuato y Puebla, quedando excluidos los territorios rurales poseedores de gran potencial turístico. En estas ciudades se abandona, paulatinamente las actividades del sector secundario y se impulsa la prestación de servicios; entre ellos destaca el turismo, ya sea cultural, de negocios, salud, congresos y compras. Esta actividad es apoyada económicamente por el Estado; quieren hacer de las ciudades parques temáticos para atraer al turismo nacional e internacional, relegando a un segundo término al turismo rural. Esta política debe orientarse a aprovecharse el espacio rural para diversificar la oferta turística, con el objetivo de impulsar el desarrollo territorial rural; es el caso del territorio poblano.

En las últimas décadas el estado de Puebla ha buscado fortalecer su economía a través de las actividades turísticas y se han observado dos variantes en su evolución: la ciudad capital ha avanzado en la vertiente de turismo de negocios y congresos; para ello se construyó el centro de convenciones de Puebla, donde se realizan importantes eventos: ferias, convenciones, congresos, etc., configurándose como el más importante y moderno segmento turístico de este tipo del centro Sur de la república mexicana. También se está impulsando el turismo de 
«ciudades y de compras», para ello se han realizado importantes obras; entre ellas destaca la construcción del centro comercial Ángelopolis y el mejoramiento de la imagen urbana del centro histórico de la capital del estado.

En la segunda vertiente se menciona al turismo arqueológico, etnográfico, ecológico y de aventura, que no ha sido aprovechado a plenitud por el bajo desarrollo empresarial, de infraestructura y de subvenciones del estado dentro de una política de inversión. Otro importante punto es la construcción de carreteras de cuota, que han permitido disminuir el tiempo de traslado de la capital a las principales ciudades donde existen centros industriales de importancia en el estado. Con las inversiones en infraestructura se espera que se beneficie y se incremente la afluencia de turistas para visitar el interior del estado.

El turismo en Puebla, específicamente el de ciudad, ha tenido momentos importantes, ha logrado colocarse entre los primeros lugares en ocupación hotelera en la categoría de «ciudades del interior», con más de 12 puntos arriba de la media nacional y por encima de destinos como Oaxaca, Monterrey y Guadalajara (plan estatal de desarrollo, Puebla, 2005: 79). En el 2006 la afluencia de turistas al estado fue de 5.751.141, el 70,3\% se concentró en la ciudad de Puebla. Se puede observar que al porcentaje restante se le puede catalogar como turismo rural, teniendo en cuenta que en las estadísticas se considera a los municipios de San Andrés y San Pedro Cholula como parte de la metrópoli Angelopolitana. El tipo de turistas que visitan Puebla son mayoritariamente nacionales; sólo el 18,3\% es de procedencia extranjera. La derrama económica en este sector fue del orden de los 437,56 millones de dólares, en el interior del estado representó el 33\% del gasto total (SECTUR, 2006).

El estado de Puebla tiene una infraestructura hotelera compuesta por 426 hoteles; el 34,5\% se concentra en la capital y aproximadamente representan el 3,2\% de la oferta nacional. Se tienen 13.203 habitaciones registradas en el Sistema de Información Turística Estatal (SITE), que equivalen al 2,5\% de la oferta nacional; los hoteles en el interior del estado tienen como máximo 3 estrellas, salvo los municipios de Izúcar de Matamoros, Atlixco, Cuetzalan, Huauchinango, Tehuacán, Xicotepec y Zacatlán, que cuentan con hoteles de 4 y 5 estrellas. La actividad turística en el estado genera 24.142 empleos de manera directa y 72.425 indirectos y se concentran fundamentalmente en la capital. El proceso de turistificación que se promueve en la capital del estado se ha visto reforzado con el crecimiento y la diversificación de la oferta restaurantera; de 732 se incrementó a 976 establecimientos en el periodo de 1999 a 2003. Se puede decir que el estado de Puebla tiene como polo turístico a su ciudad capital -municipio de Puebla-, ello se manifiesta en la centralización de la oferta hotelera, servicios, derrama económica de los turistas y en la generación de empleos. El turismo rural debido a la política turística se puede decir que es embrionario. 
Al respecto se tiene que en el estado de Puebla se promovieron diversos destinos turísticos en el ámbito rural, en el 2006, mediante el Convenio de Reasignación de Recursos entre el gobierno estatal con la Federación; éste asignó 1.143.773,11 dólares para proyectos turísticos. En Zacatlán, específicamente en el Valle de Piedras Encimadas, se invirtieron 265.876,86 dólares para el mantenimiento de edificios; en Cuetzalan, que pertenece al programa de Pueblos Mágicos y es catalogado como uno de los más exitosos, se invirtieron 326.075,41 dólares para el mejoramiento de la imagen urbana y señalización. En Xicotepec de Juárez se llevó a cabo el proyecto de aprovechamiento turístico del centro ceremonial Xochipila con un importe de 343.388,12 dólares, y en Jonotla se construyó el mirador «El Peñón» con una inversión de 208.441,17 dólares (Bretón, J. 2007: 5). En el Peñón se promueve el turismo religioso en él se venera la Aparición de la Virgen de Guadalupe, y uno de los grupos de visitantes más destacados son los originarios de esta comunidad que migraron al área metropolitana de la capital de la república. Como se puede observar, se tienen grandes inversiones, pero son insuficientes, ya que sólo apoyaron a 5 municipios localizados en el Norte del estado. En suma, se puede decir que el turismo rural en Puebla es marginal, pero tiene grandes posibilidades de desarrollarse y aprovechar las ventajas comparativas de sus territorios, como sería la belleza natural y cultural, en beneficio de la población local.

\section{OBJETIVOS Y METODOLOGÍA}

En esta investigación se plantea que el impulso del turismo rural, específicamente el agroturismo, representa una actividad complementaria que permita mejorar los ingresos de la población local, sin descuidar su principal actividad agropecuaria, que en este caso es la producción de café bajo minifundio. Es decir, que en los municipios de estudio se tiene que fomentar el desarrollo agrícola e implantar una política de desarrollo territorial rural que diversifique las actividades que se desarrollan en el ámbito rural. En este trabajo se busca relacionar la producción de café por indígenas y el agroturismo como complemento a la actividad agrícola.

La región de estudio contempla cuatro municipios que fueron seleccionados por tener plantaciones de cafetales, recursos naturales de gran valor para incursionar en actividades turísticas y población indígena considerada de muy alta marginación; ellos son: 1) Cuetzalan; 2) Huehuetla; 3) Huitzilan; y 4) Ixtepec. Se encuentran enclavados en la sierra Nororiente y se ubican entre los $20^{\circ}$ de latitud Norte y los $97^{\circ}$ de latitud Oeste. Tienen una altitud sobre el nivel del mar que oscila de los 540 a los 1000 m.s.n.m.; en la figura 1 se aprecia la ubicación de los municipios en el contexto nacional y estatal. 
Figura 1. Localización geográfica de los municipios de estudio

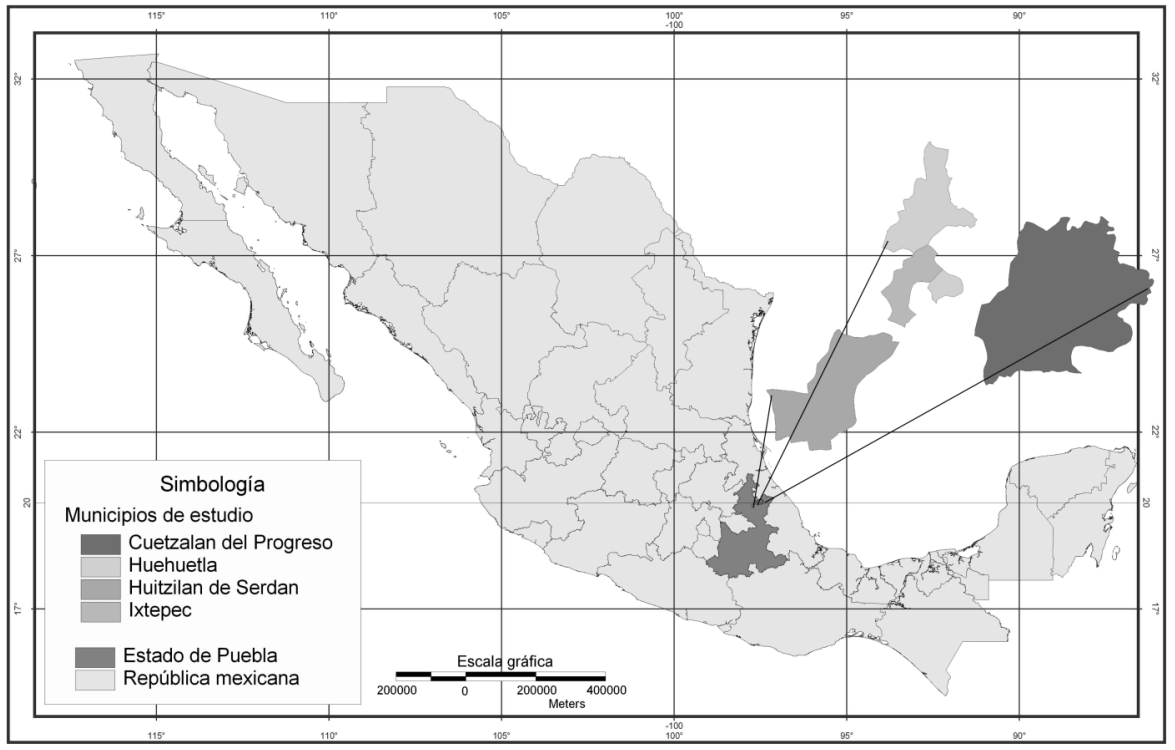

Fuente: Síntesis Geográfica del Estado de Puebla, 2000. Elaboración propia

Los principales núcleos de población de los municipios de estudio se concentran en las cabeceras municipales, los otros poblados se caracterizan por ser pequeños y dispersos, propios de los municipios rurales. El municipio de Cuetzalan tiene 45.010 habitantes, Huehuetla 16.130, Huitzilan 6.589 e Ixtepec 11.670 pobladores. Los centros poblacionales con mayor importancia poblacional o económica tienen mercado municipal, electricidad, agua potable, clínicas de salud, teléfono, Internet y biblioteca pública. En el aspecto educativo tienen escuelas de primaria, secundaria, preparatoria y una universidad intercultural en Huehuetla.

La actividad económica que predomina en los municipios es la producción de café; la población económicamente activa se emplea principalmente como jornalero, trabajador por su cuenta y trabajador familiar no remunerado. En el caso de Cuetzalan el turismo constituye la segunda actividad económica; tiene 27 hoteles: 11 son de una estrella, 3 son clasificados como de dos, 6 tienen tres, 1 posee cuatro y otro tiene cinco estrellas. El municipio de Huehuetla tiene un hotel de dos estrellas. Cuetzalan cuenta con restaurantes con excelente servicio, en Huehuetla sólo se tienen fondas; Cuetzalan cuenta con servicios de gasolineras, venta de refacciones para automóviles y farmacias. Los otros municipios carecen de estos servicios. Existen carreteras seguras, que han reducido hasta en un $40 \%$ el tiempo de traslado de la ciudad de Puebla a la zona de estudio. 
Estos resultados señalan que los espacios turísticos son incipientes en la región y los servicios turísticos están en manos de las personas que tienen mayor poder económico y social.

Los recursos turísticos de los municipios son principalmente: naturaleza, destacando la presencia de selvas; arqueología, representada por los vestigios arqueológicos de la antigua ciudad del Totonacapan; espeleología; culturas vivas, donde se acentúan los grupos indígenas totonacos y nahuas; práctica de la caficultura, su agroindustrialización y producción de maíz en ladera; y la ciudad de Cuetzalan, que es considerada Pueblo Mágico por sus características históricas, culturales y arquitectónicas.

Para calcular el tamaño de muestra de este estudio se utilizó un muestreo estratificado aleatorio, con distribución proporcional al tamaño de los municipios. El universo de muestreo estuvo constituido por los productores de café de los cuatro municipios en estudio, tomando como base el censo de caficultores realizado en 2001. La ecuación para estimar el tamaño de muestra es presentada por Gómez (1979) y se especifica de la siguiente forma:

Ecuación 1. Expresión matemática para calcular el tamaño de muestra en un estratificado aleatorio con distribución proporcional

$$
n=\begin{gathered}
\mathbf{N} \sum_{i=1}^{k} \mathbf{N}_{\mathbf{i}} s_{i}^{2} \\
\mathbf{N}^{2} \mathbf{V}+\sum_{i=1}^{k} \mathbf{N}_{\mathbf{i}} s_{i}^{2}
\end{gathered}
$$

donde:

$\mathrm{d}=$ Precisión

$Z_{\alpha / 2}=$ Confiabilidad

$\mathrm{N}=$ Tamaño de la población;

$\mathrm{N}_{\mathrm{i}}=$ Tamaño de la población del estrato i

$\boldsymbol{S}_{i}^{2}=$ Varianza del estrato i

con

$$
\mathbf{V}=\frac{\mathbf{d}^{2}}{\mathbf{Z}_{\alpha_{2}}^{2}}
$$

Con una precisión del 15\% de la media y una confiabilidad del 95\%, se obtuvo el tamaño de la muestra de 216 productores, y mediante un procedimiento aleatorio se seleccionó a los productores de café incluidos en la muestra. 
En este estudio se revisan variables de tipo social, para conocer si los agricultores indígenas están dispuestos a diversificar sus actividades, y entre ellas destaca el turismo rural; ello permitirá conocer si el agroturismo representa para los caficultores un componente complementario al desarrollo rural. Para analizar los datos se utilizó estadística descriptiva, se realizaron pruebas de t y chi - cuadrada $\left(\chi^{2}\right)$, y en los resultados se hicieron comparaciones entre indígenas productores de café interesados y no interesados en realizar actividades turísticas.

\section{LA PRODUCCIÓN DE CAFÉ Y EL AGROTURISMO}

El trabajo de investigación se centró en la posibilidad de impulsar el turismo rural, específicamente el agroturismo, en espacios marginados y con población indígena productora de café. Se indagó sobre el interés en participar en actividades turísticas por parte de los caficultores de cuatro municipios. El trabajo considera central la comparación entre productores con interés y aquéllos que no lo tienen, en participar en actividades de agroturismo, con la finalidad de entender las motivaciones de los productores y así hacer propuestas turísticas que apoyen el desarrollo y mejora de las condiciones de vida de las familias indígenas.

El idioma representa un atractivo importante en el turismo cultural; al respecto, los habitantes de los municipios de Cuetzalan y Huitzilan en su totalidad hablan náhuatl, en Huehuetla el 35\% de los productores dijo que su lengua materna es el Totonaco y el 30\% en Ixtepec. En el 2000, en México, de acuerdo al Instituto Nacional para la Evaluación de la Educación (INEE) existían un total de 10.185.060 indígenas y representaban el 10,45\% del total nacional (INEE, 2006: 63). El estado de Puebla ocupa el cuarto lugar en población de habla indígena, concentra el 9.4\% del total nacional, habitan el territorio poco más de 550 mil indígenas y representan el 13\% de la población total. Las principales etnias indígenas son las siguientes: náhuatl (73,7\%), totonaco $(17,8 \%)$, popoloca $(2,6 \%)$, mazateco $(2,1 \%)$, otomí $(1,5 \%)$, mixteco $(1,5 \%)$ y tepehua $(0,5 \%)$. Esto indica que se tiene un excelente potencial turístico en los municipios de estudio para atraer turistas en este segmento del mercado.

Las plantaciones de café de los campesinos que quieren participar en actividades turísticas de acuerdo al trabajo de campo indican que tienen en promedio 1,54 y 1 hectárea los que no tienen interés en esta actividad. No existe diferencia estadística entre los grupos $(t=1,769 ; \mathrm{p}=, 078)$ con respecto al número de hectáreas en posesión. En la sierra Nororiente el promedio de la tierra dedicada al café es de 0,85 hectáreas (Romero, 2006: 3), la cual es muy similar a la que tienen los que no desean participar en proyectos turísticos. En este sentido, destaca Cánoves, et al. (2005: 69) que es importante tener tierras para practicar el agroturismo y que en el caso español, en la modalidad de agroturismo, se exige tener una determinada superficie dedicada a la agricultura. 
Con respecto a la propiedad de la tierra, el 92.1\% dijo que sus tierras pertenecen al régimen de la propiedad privada; este resultado posibilita la inversión de capital en los municipios, ya que algunos autores mencionan que el tipo de propiedad, y en especial la pública, frena la inversión, y no es la excepción en el sector turístico. Al respecto, Echeverría y Bello (2002: 3) mencionan que la importancia de la tierra en el medio rural abarca aspectos económicos, ambientales, sociales y culturales. Además, comentan que es un medio para acumular bienestar, para atraer inversiones y permite generar ingresos en actividades agrícolas y no agrícolas.

El cuadro 1 muestra que el 80\% de los caficultores están dispuestos a incursionar en actividades turísticas; además, pone de manifiesto que en los municipios con mayor infraestructura hotelera y experiencia en servicios turísticos, como Cuetzalan y Huehuetla, los entrevistados están menos interesados en esta actividad, debido a que piensan que tienen que invertir mucho dinero en la infraestructura de alojamiento, restaurantes y espacios recreativos y que no están a su alcance. Otra situación es que los productores consideran que es una actividad que está siendo explotada por los pobladores que tienen mayores recursos económicos en la comunidad y, por lo tanto, está fuera de sus posibilidades. Es claro que para este tipo de turismo se pueden realizar inversiones de bajo costo, en donde participe la comunidad activamente en la construcción de su desarrollo.

Tabla 1. Productores a los que les gustaría participar en actividades turísticas

\begin{tabular}{|c|c|c|c|c|c|c|}
\hline \multirow{3}{*}{ Municipio } & \multicolumn{4}{|c|}{ Productores a los que les gustaría participar en actividades } & \multirow{2}{*}{\multicolumn{2}{|c|}{ Total }} \\
\hline & \multicolumn{2}{|c|}{ S } & \multicolumn{2}{|c|}{$\mathrm{N}$} & & \\
\hline & $\mathrm{F}$ & $\%$ & F & $\%$ & F & $\%$ \\
\hline Cuetzala & 7 & 7 & 2 & 2 & 10 & 10 \\
\hline Huehueti & 2 & 6 & 1 & 3 & 3 & 10 \\
\hline Ixtepe & 2 & 9 & 2 & 7 & 3 & 10 \\
\hline Huitzila & 4 & 9 & 2 & 4 & 4 & 10 \\
\hline Total & 16 & 8 & 4 & 2 & 21 & 10 \\
\hline
\end{tabular}

Fuente: Elaboración propia, encuesta a agricultores en 2005

Es importante destacar que las personas que desean participar en actividades turísticas perciben que son más pobres que las del otro grupo, debido a que el $40 \%$ mencionó que son los más pobres de la comunidad, contra el 17\% de los no participantes. Es por ello que el $92 \%$ de los participantes consideraron que pueden mejorar su ingreso y el 63\% de los que no desean participar opinó lo mismo. Berdegue, et al. (2001: 185) encuentran que la ausencia de fuentes no agrícolas de ingreso, en los hogares rurales pobres sería varias veces mayor la 
magnitud de su pobreza que los que tienen alguna fuente de ingreso no agrícola. Las mismas investigaciones confirman que los hogares rurales pobres recurren al empleo no agrícola no sólo para elevar su ingreso total, sino para amortiguar durante el año las fluctuaciones del ingreso, que es una de las características de la pobreza rural. Ello muestra que el agroturismo puede ser una actividad complementaria a la actividad agrícola que realizan cotidianamente los caficultores y, especialmente, los que consideran que tienen mayores niveles de pobreza. El turismo rural puede revitalizar la economía de este tipo de agricultores.

En el turismo rural existen diferentes modalidades; una de ellas es el agroturismo, el cual consideramos es el más apropiado para que participen de manera más inmediata en la prestación de servicios turísticos los caficultores; al respecto, Sayadi y Calatraba (2001: 132) mencionan que en términos generales es un tipo de turismo rural en donde el componente importante de la oferta turística es la acogida, alojamiento, gastronomía, ocio y la participación en la explotación agraria. Ernesto Barrera (2006: 74) es más específico y menciona que se caracteriza porque el visitante participa activamente de las actividades productivas. Esta conceptualización es la que se apega más a nuestro estudio; es por ello importante conocer la tecnificación de las actividades más relevantes del proceso productivo que se realiza en las plantaciones de café y que se considera que les gustaría conocer y practicar a los turistas. El conocimiento del proceso productivo del café representa una actividad pedagógica para los turistas, ya que en el mundo rural el paisaje y la tranquilidad no son suficientes para retener a gran parte de la población urbana. Este tipo de turismo es actualmente muy apreciado en los países desarrollados. En contraparte, en los países con menor desarrollo existen zonas rurales deprimidas económicamente, pero con potencial turístico. Un ejemplo es el caso de las fincas cafetaleras en Colombia, donde los propietarios reciben y alojan a visitantes y les hacen participar en el proceso productivo del café (Gurría, 2000).

Las personas que desean participar en turismo tienen 15,4 años trabajando sus plantaciones de café y el otro grupo tiene 18,9 años. Se encontró que no existe diferencia estadística entre los grupos ( $\mathrm{t}=-1,937$; $\mathrm{p}=, 054)$, ello muestra que los caficultores tienen experiencia en el manejo de las plantaciones y que puede convertirlas en producto turístico si se maneja adecuadamente. Un trabajo importante en el proceso productivo del café es el control de las malezas, y que interesaría realizar a los turistas; el $82 \%$ de los que quieren participar en actividades turísticas lo realiza; de este porcentaje el 83,5\% lo hace de manera manual y el 6,5\% utiliza productos biológicos. El $88 \%$ de los no interesados controlan las yerbas, sólo el 2,7\% de éstos realizan esta actividad empleando productos químicos y el 94,6\% manualmente. Con respecto a la aplicación de 
fertilizante químico, el 27,2\% de los que desean participar en turismo lo aplican y el 9,5\% de los no interesados. El fertilizante orgánico es más empleado, ya que el $45 \%$ de los interesados y el $21,4 \%$ de no interesados lo manejan.

La poda en los cafetales no es muy común, el 45 y el $21 \%$ de los que desean no participar mencionaron que la realizan. El 77 y el 83\% de los interesados y no interesados en actividades turísticas dijo tener plagas o enfermedades en sus plantaciones; la principal plaga que tienen los cafetales es la broca; en el grupo de los interesados lo mencionó el 62,4\% y en el otro grupo el 65,7\%. La controlan mediante prácticas culturales, productos químicos y de manera biológica. Estos resultados ponen de manifiesto que la tecnificación de las plantaciones de café no es muy adecuada, es por ello que se tiene que capacitar a los caficultores en el control de malezas, aplicación de fertilizante, en la poda y en el control de plagas, que permita tener la plantación en condiciones óptimas para los posibles visitantes.

Para hacer atractivas las prácticas productivas deben de proporcionarle una orientación didáctica, ya que se plantea un turismo activo en el que a priori se requiere una implicación participativa del turista (Vera, et al. 1997, 55). Es por ello que una de las vertientes a seguir en las plantaciones es la producción de café orgánico. Al respecto, se encuentra que 79,1\% de los que desean participar han escuchado hablar de la producción de café orgánico y el 85,3\% de los no participantes. Estas personas consideran que representa un buen negocio económico producirlo; además, desearían iniciar su producción y también mencionaron que saben cómo producirlo. Éste es otro producto interesante para que se promueva el consumo y comercialización del café orgánico entre los turistas, beneficiando aún más a las comunidades rurales.

A su vez, la capacitación también repercutirá en el incremento de la producción y calidad del café a cosechar, lo que representa una gran importancia, debido a que, por un lado, se benefician los productores con la presencia y consumo de turistas, y por otro lado, se mejora la tecnología, la productividad, la calidad del producto y los ingresos obtenidos de la venta del café. Este tipo de prácticas más la recolección del café, y específicamente el orgánico, son un excelente producto que interesa a los turistas y que la población local puede brindar. Pero no sólo con capacitar se logrará que la tecnología sea adoptada por los agricultores, es necesario diseñar una estrategia de desarrollo agrícola que contemple la asesoría técnica, el crédito y la provisión de insumos.

Otro producto que se puede brindar en las fincas cafetaleras, es mostrar cómo se procesa el café para el consumo. Al respecto, las personas que desean participar en la prestación de servicios turísticos, el 38,5\% mencionó que lo vende en la planta, el $36,7 \%$ en cereza y el $21 \%$ en la planta y en cereza. Los que no 
quieren participar, el 52\% lo vende en la planta, el 38\% en cereza y el 9,5\% en ambos. Las principales causas por las que no proporcionan valor agregado, mencionan que no tienen equipo (38\%) y porque no tienen dinero para comprar éste (36\%). En el otro grupo mencionan que no tienen el equipo $(55,6 \%)$ y que no disponen de capital $(29,6 \%)$. El grupo que desea participar, el 45,6\% comentó que le agradaría proporcionar valor agregado a su producción de café y el 35,7\% de los no interesados realizó comentarios similares.

La gran mayoría comenta que le agradaría vender su producto proporcionándole valor agregado, como es la venta del producto en forma de café pergamino, y muy pocos, café molido. Como podrá observarse, es importante que se impulse entre los cafetaleros el proporcionar valor agregado a su producción, específicamente en el beneficiado que consiste en: despulpar y lavar el café; secado en zaranda; trillado (en mortero de madera); selección de grano; tostado y molido, y empacado. Estas prácticas propias de la agroindustria son demasiado interesantes y didácticas; en ellas se busca que los turistas se involucren realizando cada una de ellas y, a su vez, conozcan como se produce el café que degustan. Con ello se busca relacionar las plantaciones de café con el turismo para proporcionar valor añadido a estos espacios.

Para su impulso se requiere apoyo económico a los agricultores para la compra de equipo, desde el beneficiado hasta el empaque del café; esta actividad agroturística traerá beneficios económicos directos a los cafeticultores, al mejorar su ingreso por la venta de café y por la atención de turistas en su hogar. Un ejemplo es el caso colombiano, que ante el deterioro de sus condiciones de vida, los habitantes del eje cafetero buscaron alternativas de diversificación del ingreso. El caficultor, ante la necesidad de transformar sus explotaciones agropecuarias, se reconvirtió y recurrió a estrategias adaptativas diversas que implicaron una nueva organización productiva y espacial. Es así como los caficultores decidieron que sus plantaciones de café no sólo servían para exportar «the richest coffee in the world», sino también, para atraer turistas y generar ingresos complementarios (Ramírez, 2002: 2).

Es un ejemplo que se puede aprovechar con los pequeños caficultores de la localidad. También es importante que se aprovechen los determinantes exógenos sobre la prestación de servicios que están demandando -casas de fin de semana, restaurantes tradicionales, espacios de paseo, pesca y diversión- los habitantes de las grandes ciudades como la de México y Puebla. El turismo rural, y en especial el agroturismo, es un instrumento que puede impulsar la economía de los caficultores y con ello mejorar sus condiciones de vida al incorporar a los turistas en las prácticas agrícolas y agroindustialización que realizan los caficultores. 


\section{CONCLUSIONES}

Se encuentra que existe un porcentaje importante de caficultores que están dispuestos a incursionar en actividades turísticas; para ello es necesario diseñar programas de financiamiento para participar en el servicio de hospedaje y en la infraestructura complementaria para los turistas. Además, se tienen que promover proyectos que contemplen su capacitación para incursionar en el turismo, con temas de administración de casa rurales, contabilidad, recursos humanos, entre otros no menos importantes. Es necesario desarrollar políticas de turismo rural, para aprovechar que en los municipios de estudio los caficultores participen en este tipo actividades para complementar el ingreso que obtienen de su producción.

Es importante combinar la actividad agrícola con el agroturismo, ya que en conjunto, coadyuvarán a mejorar la calidad de vida de los habitantes de la localidad. Para ello se deben emprender proyectos agroturísticos que apoyen con recursos económicos y capacitación a los caficultores. En primer lugar, en la producción de café convencional y orgánico; en éste tienen que participar la Secretaría de Agricultura, Ganadería, Pesca y Alimentación (SAGARPA) y el Consejo Poblano del Café mediante la capacitación de los caficultores en el proceso productivo y a enseñarles a proporcionarle valor agregado. En segundo lugar, se tiene que diseñar una estrategia de financiamiento para la compra de insumos para aplicar lo aprendido en la capacitación; también se debe financiar la compra de maquinaria y equipo para dar valor agregado al café.

Se puede decir que se tienen que reconvertir las unidades de producción y casas rurales para uso turístico para lograr que se incrementen los ingresos de los caficultores. Si Cuetzalan es un ejemplo exitoso, es necesario extender la actividad turística a los municipios circunvecinos de manera ordenada y planificada para no degradar los recursos naturales, que de una u otra manera, en el mediano plazo, se realizarán esfuerzos aislados y desordenados por explotar la activad turística. Es necesario planificar de manera integral el espacio turístico rural, donde los habitantes de las comunidades participen activamente en su propio desarrollo.

Pero también es importante promover entre los turistas que visitan la ciudad de Puebla el turismo de interior y ofrecerles a Cuetzalan -Pueblo Mágico-, debido a su experiencia en este ramo, y hacer de ella una región turística polinuclear. Para ello se propone que se desarrolle una ruta turística -del café-, que tenga como polo de desarrollo a Cuetzalan y que en su hinterland los caficultores ofrezcan en sus casas productos agroturísticos, basados fundamentalmente en el atractivo de incorporar a los turistas a realizar trabajos en el proceso productivo del café y en su participación en proporcionarle valor agregado. Se esperaría una fuerte aceptación de esta ruta. Con este tipo de productos se diversifica la oferta turística y se contribuye a romper la estacionalidad de la actividad turística. 


\section{BIBLIOGRAFÍA}

Amaya, C. M. (2005): «Desafíos y oportunidades del turismo rural en México». En Desarrollo rural y turismo, Editores: Dachari, A. C., Orozco, J. y Arnaiz, S. México, Universidad de Guadalajara, Centro Universitario de la Costa y Universidad de Buenos Aires, Facultad de Agronomía, pp. 51-57.

André Sarasa, J. L. (2000): «Aportaciones básicas del turismo al desarrollo rural», en Cuadernos de Turismo, nº 6, pp. 45-59.

Ascanio Guevara, A. (2004): «Turismo y desarrollo de la comunidad, un primer paso para rescatar la identidad cultural», en Pasos. Revista de Turismo y Patrimonio Cultural, vol. 2 n², pp. 155-161.

Berdegué, J. A.; Reardon, T. y Escobar, G. (2002): La creciente importancia del empleo y el ingreso rurales no agrícolas. En Echeverrí, R. G. (editor) Desarrollo de las economías rurales en América Latina y el Caribe. Banco Interamericano de Desarrollo, 275 pp.

Boletín de Prensa, octubre (2006): Nuevo León, México.

Bretón Ávalos, J. J. (2007): Avances y resultados 2006. Secretaría de Turismo, México, $12 \mathrm{pp}$.

Cánoves Valiente, G.; Herrera Jiménez, L. y Villarino Pérez, M. (2005): «Turismo rural en España. Paisajes y usuarios, nuevos usos y nueves visiones», en Cuadernos de Turismo, n 15, pp. 63-76.

Damiani, O. (2002): Pequeños productores rurales y agricultura orgánica: lecciones aprendidas en América Latina. FIDA, 75 pp.

Echeverría, R. G. y Bello, N. (2002): «Opciones para fomentar el acceso a tierras». En Banco Interamericano de Desarrollo (comp.) El acceso a la tierra en la agenda de desarrollo rural. Serie de Informes Técnicos del Departamento de Desarrollo Sostenible, BID, pp. 1-23.

EcheVerri, R. y Ribero, M. P. (2002): Nueva ruralidad. Visión del territorio en América Latina y el caribe. Instituto Interamericano de Cooperación para la Agricultura, $207 \mathrm{pp}$.

BIRF y BM (2005): Generación de ingreso y protección social para los pobres. Banco Internacional de Reconstrucción y Fomento / Banco Mundial, 218 pp.

Font, X. (2006): «Turismo Sostenible: factor fundamental para la erradicación de la pobreza en Colombia». Informe del IV Seminario Internacional Organización Mundial del Turismo, 52 pp.

Gobierno del estado de Puebla (2005): Plan estatal de desarrollo 2005-2011. Gobierno del estado de Puebla, 272 pp.

Gómez, R. (1979): «Introducción al muestreo». Chapingo, México, Tesis de Maestría en Ciencias en Estadística. Centro Estadística y Cálculo. Colegio Postgraduados. 
GuRRía Di-Bella, M. (2000): «El turismo rural sostenible como una oportunidad de desarrollo de las pequeñas comunidades de los países en desarrollo», en Cuarta Feria Ecoturística y de Producción, 15 - 23 Julio, Buena Noche de Hato Nuevo, Manoguayabo, Santo Domingo, República Dominicana, disponible en web: http://www.kiskeya-alternative.org/publica/diversos/rural-tur-gurria. html, pp. 10.

KAY, C. (1998): «Estructuralismo y teoría de la dependencia en el periodo neoliberal. Una perspectiva latinoamericana», en Nueva Sociedad, n 158, pp. 100-119.

Linck, T. s/f, «La economía y la política en la apropiación de los territorios». INRA - Systèmes de Décision pour le Développement, disponible en web: www.gis-syal.agropolis.fr/PDF/TLinck.pdf

IICA y BID (2003): Experiencia de atención a la pobreza y municipalización en el desarrollo rural sostenible. IICA y BID, 222 pp.

INEE (2006): Panorama educativo de México 2005. Indicadores del Sistema Educativo Nacional. Instituto Nacional para la Evaluación de la Educación, $549 \mathrm{pp}$.

Juárez Sánchez, J. P. y Ramírez Valverde, B. (2007): «El turismo rural como complemento al desarrollo rural en zonas indígenas de México», en Scripta Nova, abril.

Lustig, N. y Székely, M. (1997): México: evolución económica, pobreza y desigualdad. Washington, D.C., PENUD, BID y la CEPAL, 47 pp.

OMT (2003): Turismo y atenuación de la pobreza. Organización Mundial del Turismo, $119 \mathrm{pp}$.

PÉREZ, E. (2005): «Hacia una nueva visión de lo rural», en GIARRACCA, N. (comp.) ¿Una nueva ruralidad en América Latina? CLACSO, 384 pp.

Ramírez Vallejo, J. (2002): «Agroturismo como alternativa de diversificación del ingreso en el eje cafetalero colombiano», en Harvard Review of Latin America, Tourism in the Américas. Development, Cultura and Identity, págs. 5.

Ramos, J. (1993): «Crecimiento, crisis y viraje estratégico», en Revista de la CEPAL, no. 50, agosto, pp. 34-49.

RoMeRo, J. L. (2006): Modelos productivos regionales durante la crisis de bajos precios del café, en el estado de Puebla. Consejo Poblano del Café, Gobierno el estado de Puebla, 44 pp.

SASSANO, S. (2001): «Transformaciones de un espacio urbano: El caso del mercado de abasto de Buenos Aires», en Anales de Geografía de la Universidad Complutense, n²1, pp. 99-118.

Sayadi, S. y Calatraba, J. (2001): «El agroturismo y desarrollo rural: situación actual y potencial y estrategias en zonas de montaña del Sureste español» en Cuadernos de turismo, n 7 , pp. $131-157$. 
SECTUR (2001): Resumen Ejecutivo. Estudio estratégico de viabilidad del segmento ecoturístico en México. SECTUR e ITAM, 14 pp.

SECTUR (2006): El turismo 2001 - 2006. Secretaría de Turismo del Estado de Puebla. Gobierno del estado de Puebla, 33 pp.

Schejtman, A. y Berdegué, J. (2004): Desarrollo territorial rural. Chile, Centro Latinoamericano para el Desarrollo Rural, Debates y Temas Rurales, no 1, 53 pp.

Silva Pérez, R. (2002): «Estrategias de inserción de las áreas rurales en la economía mundial. Una aproximación desde Andalucía», en Boletín de la Asociación de Geógrafos Españoles, n 33, pp. 103-131.

Vera, F; López Palomeque, F; Marchena, M. y Antón, S. (1997): Análisis territorial del turismo. España, Ariel, 443 pp. 